\title{
The Continued Need for Diversity in Fraud Research
}

\author{
Vikas Anand · M. Tina Dacin · Pamela R. Murphy
}

Received: 3 December 2014/ Accepted: 3 December 2014/Published online: 20 December 2014

(C) Springer Science+Business Media Dordrecht 2014

\section{Introduction}

The motivation for this special issue arose when two of the co-editors discovered they had similar interests in fraud research, but from different vantage points. Each used different theoretical foundations and methodologies, yet each had interesting insights to share with regard to fraud within organizations. They planned a conference in which a set of researchers from accounting and the management and organizational behavior fields were invited to come together and discuss their research. While the insights gained from the presentations were useful in themselves, especially notable was how each set of researchers appeared surprised by the insights, approaches, and methodologies used in each field. There arose a strong perception that each discipline's approach could potentially benefit and inform the other.

This special issue was thus born with the clear understanding that fraud is a difficult phenomenon to understand, much less prevent, and that it persists within organizations even when many preventive mechanisms (e.g., controls, policies, regulations) are in place. However, key approaches to studying fraud should emphasize its diversity. Because fraud is diverse with respect to the underlying means, motives, and actors who commit it, fraud research must draw on diverse theoretical and empirical approaches in order to understand this pervasive phenomenon.

\section{Anand}

University of Arkansas, Fayetteville, USA

M. Tina Dacin · P. R. Murphy $(\bowtie)$

Queen's University, Kingston, Canada

e-mail: pmurphy@business.queensu.ca
In our call for papers, we requested submissions that cut across academic disciplinary lines and offered theoretical and practical implications for organizational members. Although submissions could address any fraudrelated issue, we discussed two themes. The first theme addressed the differences between fraud and unethical behavior within organizations. What are the boundaries between fraud and unethical behavior? What are the antecedents to fraud and are they different than the antecedents to unethical behavior? Our second theme was simply fraud prevention. How can fraud be prevented? What mechanisms can be put in place within organizations to help them reduce the likelihood of fraud occurring?

We received many submissions, each going through a rigorous review process. While the majority of submissions were assigned two blind reviewers, we also used three in some cases. We are delighted, and not surprised, to see that the eight articles in this special issue represent the crossdisciplinary approach we requested, and these articles address a wide variety of fraud topics using different theories and methodologies. Not all the themes in our call are addressed, though, but that is to be expected given the limitations on the number of submissions and the number that can be accepted for a special issue.

This essay introduces the special fraud issue while also highlighting areas that we believe deserve more attention from researchers. The next section will address our first point about diversity: fraud is defined and perpetrated in a multitude of ways and by different sets of perpetrators; thus, it must be explored in a multitude of ways. Next, we discuss fraud-prevention mechanisms, along with their intended and unintended consequences. Finally, we discuss additional ways in which researchers can examine fraud, in order to increase our knowledge. Within each section, we 
include discussions of the articles contained in this special issue along with calls for future research.

\section{Diversity of Fraud Conceptions and Ways it is Perpetrated}

Fraud is a slippery word. Definitions of fraud differ, as do conceptions of ethical versus unethical behavior. Different societies, organizations, groups, and individuals may view fraud and unethical behavior differently, and those views can change over time and by context. Not only that, but fraud can be committed by individuals alone as well as groups of individuals working together. These groups can be as small as two individuals all the way to entire organizations or societies.

\section{Conceptions of Fraud}

The articles in this issue examine several different "types" of fraud, including internal employee fraud and fraudulent financial reporting. Internal employee fraud refers to cases in which a single employee commits fraud, such as creating false billing schemes (Lowe, Pope and Samuels), misreporting one's own costs (Clor-Proell, Kaplan and Proell), or deceiving others within the organization (Smith-Crowe, Tenbrunsel, Chan-Serafin, Brief, Umphress and Joseph). Fraudulent financial statements involve the intentional misstatement of an organization's financial results or economic position, examined by Albrecht, Holland, Malagueno, Dolan and Tzafrir as well as Chakrabarty. These frauds are different in nature and are likely to have different antecedents and consequences. For example, false billing schemes are most easily perpetrated by someone who has access to the billing function as well as the accounting function. Fraudulent financial statements are generally perpetrated by individuals higher up in the organization (often involving the CEO or CFO) and are deemed to be the most costly to organizations (ACFE 2014).

Two other interesting conceptions of fraud included in this special issue are fraud perpetrated by customers (Perezts and Picard) and the demand to commit fraud faced by a supplier organization (Pierce and Snyder). These unique situations likely contain very different antecedents to fraudulent and unethical behavior, not to mention negative outcomes on employees and the organizations involved. An organization's willingness to condone the fraudulent use of its products and services appears to occur in a variety of settings today (e.g., music sharing, spying on individuals, the use of classified advertisements for illegal activities, and so on) but has received relatively little attention in the literature. This opens up a very interesting future research direction.

The types of fraud examined by the manuscripts in this special issue only scratch the surface of possibilities. The Association of Certified Fraud Examiners (ACFE) lists 44 different types of fraud schemes perpetuated within organizations (ACFE 2014), not even counting nonmonetary "frauds" such as intentionally ignoring product safety concerns or polluting the environment. In addition, the papers in this special issue raise at least two other issues. First, whether the fraud was on behalf of the company versus against the company. For instance, Albrecht et al. examine how groups can be coopted to enact fraud on behalf of the firm, while Chakrabarthy raises the issue (among others) of how a subunit within an organization can take advantage of information asymmetry to mask performance (or capture excess resources) from headquarters' or other units of a diversified firm. The papers in this issue and much of the existing literature in management and accounting have not fully examined differences in perpetrator or organizational characteristics which differentially influence or inhibit the two types of fraud. This is an important area of future research.

\section{Perpetrators of Fraud}

Fraud can be perpetrated by individuals acting alone or in groups, with groups consisting of a few, many, or entire organizations or societies. Within this issue, several articles address fraud and fraud prevention with an individual employee in mind, while others take the view that fraud may be perpetrated by groups. Fraudulent financial statements are almost always perpetrated by groups of individuals, led by someone in top management.

Nevertheless, management and accounting research have both primarily focused on individual-level research as opposed to group-level research (see Treviño et al. 2006). Within some studies in the literature, fraud is portrayed as being perpetrated by an individual who has some type of character flaw (Morales et al. 2014), or as perpetrated by individuals influenced by their social group (Sutherland et al. 1992) or influenced by external groups such as consumers (Pierce and Snyder). Given this paucity of grouplevel research, it is encouraging to see papers such as Albrecht et al.'s which specifically examine group-level research. While the special issue represents a small step in examining group-level fraud research, this remains an important but under-researched phenomenon.

We call for a continuation of research focused on a broader set of all types of perpetrator groups, including some research that can use theories and insights from both disciplines as well as others. 


\section{Fraud-Prevention Mechanisms}

Our call for papers also requested submissions that examined ways in which fraud could be prevented within organizations. Several articles within this issue directly or indirectly examine fraud prevention. Clor-Proell et al. find that, when organizations set difficult goals for employees, fraud likelihood can be reduced by promotion availability. Rodgers et al. highlight the role of corporate social responsibility in designing controls to thwart fraud. SmithCrowe et al. examine the effect of countervailing systems (formal and informal) on fraudulent behavior. Perezts and Picard's case study on a bank's compliance-implementation of anti-money laundering finds benefits to compliance when it is organizationally part of the businesses themselves, with analysts who use professional judgment and a risk-based approach rather than a check-list mentality. Finally, Chakrabarty finds that organizations that are diversified in a related manner (vs. unrelated) have a lower incidence of fraudulent financial statements, contingent on the moral character of the organization. All of these studies provide valuable insights into the kinds of situations in which fraud is more or less likely to occur.

Some of the articles address unintended consequences of fraud-prevention mechanisms or information that might mistakenly imply an ethical environment. For example, Lowe et al. find an unintended consequence to the certification requirement within the Sarbanes-Oxley (SOX) Act of 2002. SOX requires the CEO and CFO to certify their organization's financial statements and certify that they are unaware of fraud. In response to that requirement, many organizations implemented a subcertification process in which similar certifications are required along the chain of command. Lowe et al. find that, in organizations that use subcertification, an employee is less likely to blow the whistle on a superior who is perpetrating fraud when that superior signs a certification. Pierce and Snyder examined a particular situation in which employee turnover is lower and employees may think they their behavior is "prosocial." However, this situation is one in which customers demand fraud and the responding organizations and employees meet that demand. Their study demonstrates that both the corrupt employees and corrupt organization benefit through financial rewards and longer tenure. Findings such as these highlight that all is not as it may seem. While we may be comforted by certain statistics or by regulations that are intended to reduce fraud, fraud may actually be present and growing. It is critical to be aware of these unintended consequences. In fact, Albrecht et al. also find that individuals are able to rationalize fraud as being in the interests of the company and are often recruited by those in power; hence, the pressure is great, and the perpetration goes unquestioned.
Importantly, practitioners are interested in fraud-prevention mechanisms that are efficient, not just effective. Smith-Crowe et al. examine the effect of countervailing forces of a formal system that encourages ethical behavior and an informal system that encourages unethical behavior. They find that the formal system is more effective when the informal system pushes for unethical behavior; however, when the informal system does not push for unethical behavior, the formal system does not have an impact on fraud likelihood. This finding is important to understanding the costs and benefits of fraud-prevention mechanisms. We note an analogy to audit research. Audit research in fraud detection has focused almost exclusively on the effectiveness of fraud-detection methods. While this research stream is important and informative, we encourage research that also examines the efficiency of various frauddetection methods.

\section{Ideas for Future Research}

The articles herein use many different theoretical frameworks, methodologies, and other innovations. Several theories were used, from those related to organizations (i.e., institutional theory) to fraud itself (i.e., fraud triangle). While the fraud triangle framework has been used in a vast majority of accounting and auditing research, we note that the fraud triangle has come under criticism of late (Morales et al. 2014). We encourage this debate as we work together to tweak existing theories or create new theories that capture the vast array of how fraud is perpetrated. We have yet to discover a "theory of fraud," nor do we believe one exists, due to the diversity of fraud itself. We must continue striving to identify the theoretical frameworks that can capture different types of fraud.

Similarly, we note that the researchers published herein used different methodologies, from experiments to the use of archival data to an ethnographic case study. They also used creativity in how they used those methodologies. For example, Pierce and Snyder used the Department of Motor Vehicles data to identify "corrupt" organizations versus "corrupt" employees. Smith-Crowe et al. used data from a national business ethics survey to operationalize formal and informal systems within organizations. Albrecht et al. use interviews, court records, and other documentation, along with the use of existing theories to build a model that may shed light on how individuals use power to recruit others into a fraudulent financial reporting scheme. Perezts and Picard used a combination of participant observation (an internship with a bank), interviews, and other documentation to understand how compliance is implemented within a bank. We encourage the continued use of multiple 
methods and creativity in seeking a better understanding of fraud and fraud prevention.

\section{Situational Factors and Unintended Consequences}

There are two other themes in the articles of this special issue that we encourage. The first is that they generally all examine situational, or contextual factors, rather than identifying the characteristics of fraud perpetrators themselves. While we know that the antecedents of fraud are a mix of fraudster dispositions and situations that lead to fraud, we argue that more is known about the dispositions of fraudsters (i.e., Jonason and Webster 2010) than the situations or contexts in which fraud is perpetrated. This may be due to the sheer number of possible situational factors, singly and in combination. We urge more research that delves into these situational factors. For example, are the antecedents of fraud perpetrated by individuals the same as for groups or the entire organization? Are certain prevention methods more successful for fraud committed by individuals, groups, or an organization? Are certain prevention methods more successful for certain types of fraud? In this issue, Rodgers, Soderbom, and Guiral examine the use of an Ethical Process Throughput Model (EPTM) to assist with analyzing complex ethical situations. Combining this model with the fraud triangle, the authors suggest that this framework will enable individuals and organizations to have greater awareness of the ethical implications of their decisions.

The second theme in some of the articles has to do with unintended consequences. Using the theme of unintended consequences, we call for research into the role of innovation in the perpetration of fraud. While innovation is seen as a positive within organizations, could it have a dark side? Is an innovative organization equally innovative when it comes to committing fraud? To what extent do innovations in technology, finance, or management practices promote fraud within organizations? In the context of compliance, Perezts and Picard seek to understand the role of compliance professionals in the financial services sector as they navigate the line between the letter of the law (or the script of regulation) and their comfort level in enforcement. The reverse may also be true-can the use of processes and procedures aimed at reducing fraud also curb innovation and flexibility within an organization? For instance, many organizations react to the presence of fraud by developing procedures such as a mandatory referral of any decision with an ethical component to an ethics or legal officer. The need for referral may prevent individuals from carrying through on innovative ideas or delay decision making while waiting for approval. In such situations, research that examines how organizations can curb fraud without simultaneously disempowering employees could be another promising direction for future research.

\section{Fraud Versus Unethical Behavior}

While we believe this special issue provides both theoretical and practical insights into fraud and fraud prevention, some issues remain unfulfilled. One issue not explicitly addressed is the differentiation between legal fraud (fraud that clearly contravenes existing laws) and moral/ethical fraud (actions that misrepresent key information in contravention of existing ethical norms). The articles in this special issue primarily address behavior that is unambiguously considered fraudulent. While this is important, we also note that many researchers tend to label an act as fraudulent only after a court or regulator had deemed it so. What about perceptions of that behavior before it was legally declared fraud? What causes perceptions to change, other than a court or regulator declaring it illegal? Given that some fraud perpetrators claim they did not believe what they did at the time was truly fraudulent (Free and Murphy 2014), this seems an important issue that needs further research. Relatedly, future inquiry could revolve around small acts of fraud within organizations (e.g., misuse of equipment or supplies, over-ordering meals). While such occurrences in isolation are not problematic, they can add up to significant costs over time. These "invisible" acts of fraud become normalized over time, go unquestioned and are not considered to be within the zone or boundaries of what is considered fraudulent behavior. However, can they lead to more egregious behaviors that begin to fit our conception of fraud?

As this introduction highlights and the accompanying articles lend credence, fraud is diverse. In order to help organizations prevent fraud, research must also be diverse. It is only through the use of multiple approaches, theoretical frameworks and methodologies, that we will truly understand fraud. Then, and only then, will we be able to prevent fraud in a meaningful way.

Acknowledgments We wish to thank the special issue reviewers: Wendy Bailey, Emily Block, Carmel Branston, Denise Breaux, Kenneth Butterfield, Qiu Chen, Mary Clark, Jeffrey Cohen, Samantha Conroy, Larry Crumbley, Jon Davis, Debbie DeLange, Naman Desai, Yuan Ding, Emilija Djurdjevic, Lorraine Eden, Alan Ellstrand, Simona Giorgi, David Godsell, Ulfert Groneweld, Amy Guerber, Maretno Agus Harjoto, Dana Hermanson, Chris Hogan, Lori HolderWebb, Karim Jamal, Jonathon Johnson, Mahendra Joshi, Alison Kemper, William Kerler, Jennifer Kish-Gephart, Thomas Kozloski, Martin Larraza-Quintana, Cedric Lesage, Dan Li, Theresa Libby, Ting Luo, Marianna Makri, Maggie Matear, Ella Mae Matsumura, Bill Mayew, Brian Mayhew, Fabio Mendez, Stewart Miller, Yuri Mishina, Wren Montgomery, Joseph O'Connor, Anne O'Leary-Kelly, Timothy Pearson, Jo-Ellen Pozner, Lynnette Purda, Sridhar Ramamoorti, Shannon Rawski, Richard Riley, Alexander Rose, Karen 
Schnatterly, Paul Skilton, Karen Sonpar, Herve Stolowy, Linda Trevino, and Greg Trompeter.

\section{References}

Association of Certified Fraud Examiners (ACFE) (2014). Report to the Nations on Occupational Fraud and Abuse. June 2014, Austin TX.

Free, C., \& Murphy, P. R. (2014). The Ties that Bind: The decision to co-offend in fraud. Forthcoming in Contemporary Accounting Research.
Jonason, P. K., \& Webster, G. D. (2010). The dirty dozen: A concise measure of the dark triad. Psychological Assessment, 22, $420-432$.

Morales, J., Gendron, Y., \& Guénin-Paracini, H. (2014). The construction of the risky individual and vigilant organization: A genealogy of the fraud triangle. Accounting, Organizations and Society, 39, 170-194.

Sutherland, E. H., Cressey, D. R., \& Luckenbill, D. F. (1992). Principles of criminology (11th ed.). New York: General Hall Inc.

Treviño, L. K., Weaver, G. R., \& Reynolds, S. J. (2006). Behavioral ethics in organizations: A review. Journal of Management, 32, 951-990. 